\title{
Iron status in obese women
}

\author{
Hanna Stankowiak-Kulpa', Angelika Kargulewicz', Arkadiusz Styszyński², \\ Ewelina Swora-Cwynar ${ }^{1}$, Marian Grzymisławski ${ }^{1}$ \\ ${ }^{1}$ Department of Internal Medicine, Metabolism and Dietetics, Poznan University of Medical Sciences, Poland \\ ${ }^{2}$ Department of Palliative Medicine, Poznan University of Medical Sciences, Poznan, Poland
}

Stankowiak-Kulpa H, Kargulewicz A, Styszyński A, Swora-Cwynar E, Grzymisławski M. Iron status in obese women. Ann Agric Environ Med. 2017; 24(4): 587-591. doi: 10.5604/12321966.1232092

\section{Abstract}

Introduction and objective. A decreased concentration of iron, and consecutively haemoglobin, ferritin and decreased level of saturated transferrin, were observed in obese individuals more often than in healthy subjects. The purpose of this study was to determine whether iron, ferritin, transferrin saturation are significantly diminished in obese female patients compared to non-obese counterparts, and whether excess adiposity and inflammation were associated with depleted iron. Materials and methods. Female patients $(n=48)$ diagnosed with obesity $\left(B M I>30 \mathrm{~kg} / \mathrm{m}^{2}\right)$, aged $18-40$ were accepted for the study. A control group $(n=30)$ encompassed normal weight women, aged $18-30$. All obese women obtained an individually adjusted dietary plan with an energy content of 1,500 kcal. Blood glucose, insulin, lipids, ferritin, TIBC and iron concentrations were assayed in serum twice, initially and after 8 weeks of dieting.

Results. The obese women at the initial evaluation, in comparison to non-obese control women, were characterized by a significantly lower mean red blood cell volume (MCV; $84.2 \pm 12.4$ vs. $91.3 \pm 9.3 \mathrm{fL} ; \mathrm{p}<0,0001)$, serum iron level (92.6 \pm 42.4 vs. $119.8 \pm 44.0 \mu \mathrm{g} / \mathrm{dL} ; \mathrm{p}<0.01$ ), and transferrin saturation (TSAT; $25.9 \pm 12.7 \mathrm{vs}$. $38.8 \pm 15.7 \% ; p<0.01$ ), but by higher plasma level of the C-reactive protein (CRP; 7.0 \pm 6.7 vs. $1.2 \pm 1.3 \mathrm{mg} / \mathrm{L} ; \mathrm{p}<0.01)$. The obese women after 8 weeks of diet decreased their mean total body weight from $104.1 \pm 21.3$ to $99.2 \pm 20.7 \mathrm{~kg}$ ( $p<0,0001)$. CRP level decreased slightly but significantly from $6.9 \pm 7.1$ to $6.2 \pm 7.5(\mathrm{p}<0.05)$.

Conclusions. Obese women exhibit an increased level of CRP which may affect iron homeostasis. Weight loss leads to decrease in the CRP level, but it does not change haematologic parameters in the period of 8 weeks.

\section{Key words}

iron, obesity, women

\section{INTRODUCTION}

Obesity is described as an enhanced storage of fatty acids in adipose tissue, and chronic activation of inflammatory pathways. Excessive body mass is an important epidemiological problem leading to the development of a variety of metabolic disorders with subsequent deterioration in overall health status $[1,2]$. Obesity correlates with cardiovascular diseases, diabetes type 2, nonalcoholic fatty liver disease, development of cancers, as well as degeneration in bone and joint structure [3]. Moreover, excessive body weight also correlates with iron deficiency. Decreased concentration of iron and consecutively haemoglobin, ferritin and decreased level of saturated transferrin were observed in obese individuals more often than in healthy subjects. This can be explained by obesity-related inflammation and increased level of hepcidin, i.e. protein that is postulated to be directly responsible for diminished iron absorption in the gut via its down-regulatory influence on iron exporter from intestinal enterocytes and macrophages, recognized as ferroportin-1.

Seltzer and Meyer identified iron deficiency in a population of obese subjects for the first time in 1962. Wenzel et al. described it consecutively in 1963. Initially, iron deficiency in a population of obese people was linked to a low level of physical activity, poor dietary habits, and increased requirement of iron related to larger blood volume and obesity. Recently, depleted iron stores in obese subjects

Address for correspondence: Angelika Kargulewicz, Department of Internal Medicine, Metabolism and Dietetics, Poznan University of Medical Sciences, Poland E-mail: angelikak610@gmail.com

Received: 3 September 2013; accepted: 23 June 2014; first published on February 2017 were linked to inflammation and hepcidin influence on iron influx into plasma through its down-regulating action on ferroportin-1 $[4,5,6,7,8]$.

\section{OBJECTIVE}

The purpose of this study was to determine if iron, ferritin, and transferrin saturation are significantly diminished in obese female patients compared to non-obese counterparts, and whether excess adiposity and inflammation were associated with depleted iron. Plasma hepcidin was not evaluated in this study.

\section{MATERIALS AND METHOD}

Obese women. Female patients $(n=48)$ diagnosed with obesity (BMI $\left.>30 \mathrm{~kg} / \mathrm{m}^{2}\right)$, aged $18-40$ were accepted for the study performed in the Department of Internal Medicine, Metabolism and Dietetics, at the University of Medical Sciences in Poznań, Poland.

The exclusion criteria involved confirmed diabetes mellitus type 2, untreated hypothyroidism from any cause, hypertension $(\mathrm{BP}>140 / 90)$, chronic renal failure (GFR $<60 \mathrm{ml} / \mathrm{min} / 1,73 \mathrm{~m}^{2}$ ), acute or chronic inflammation from any cause, smoking, pregnancy, breast feeding, menopause, heavy periods, rectal bleeding, and use of iron supplements.

Patients were assessed initially and at 8 weeks intervals. During this time-span, all individuals were on low calorie diet with limited saturated fat and simple sugars. The second 
Table 1. Anthropometric parameters and results from Oral Glucose Tolerance Test - a comparison of obese women with non-obese control

\begin{tabular}{lcc}
\hline Parameter & Obese Patients & Control Group \\
\hline Body mass $(\mathrm{kg}$, mean $\pm \mathrm{SD}){ }^{*}$ & $104.5 \pm 19.2$ & $56.4 \pm 6.5$ \\
\hline Height $(\mathrm{cm}$, mean $\pm \mathrm{SD})$ & $165.6 \pm 5.3$ & $164.8 \pm 6.4$ \\
\hline Fat content $(\%$, mean $\pm \mathrm{SD}){ }^{*}$ & $45.2 \pm 5.1$ & $22.5 \pm 3.7$ \\
\hline BMI $(\mathrm{kg} / \mathrm{m} 2$, mean $\pm \mathrm{SD}){ }^{*}$ & $38.1 \pm 6.6$ & $20.8 \pm 1.9$ \\
\hline Waist $(\mathrm{cm}$, mean $\pm \mathrm{SD}){ }^{*}$ & $107.9 \pm 14.5$ & $69.4 \pm 4.8$ \\
\hline Hip $(\mathrm{cm}, \mathrm{mean} \pm \mathrm{SD}){ }^{*}$ & $125.4 \pm 12.8$ & $96.0 \pm 5.3$ \\
\hline WHR $(\mathrm{mean} \pm \mathrm{SD}){ }^{*}$ & $0.86 \pm 0.07$ & $0.72 \pm 0.04$ \\
\hline Glucose $0^{\prime}(\mathrm{mg} / \mathrm{dl} \pm \mathrm{SD})$ & $91.3 \pm 10.8$ & $87.2 \pm 7.3$ \\
\hline Glucose $120^{\prime}(\mathrm{mg} / \mathrm{dl} \pm \mathrm{SD}){ }^{*}$ & $118.4 \pm 24.3$ & $87.9 \pm 18.8$ \\
\hline Insulin $0^{\prime}(\mu \mathrm{U} / \mathrm{ml} \pm \mathrm{SD}){ }^{*}$ & $16.4 \pm 15.9$ & $7.3 \pm 2.8$ \\
\hline Insulin $120^{\prime}(\mu \mathrm{U} / \mathrm{ml} \pm \mathrm{SD}){ }^{*}$ & $79.9 \pm 56.8$ & $41.8 \pm 27.7$
\end{tabular}

Statistically significant differences between groups marked with *

assessment was fulfilled by 29 female patients. From the initial group of patients, 19 were excluded due to lack of compliance with the dietary regime.

The study was approved by the Human Subjects Oversight Committee at the University of Medical Sciences in Poznan (No. 688/09). Informed consent was obtained from each patient included in the study.

Non-obese women. The control group $(\mathrm{n}=30)$ encompassed normal weight women $\left(\mathrm{BMI}<30 \mathrm{~kg} / \mathrm{m}^{2}\right)$, aged $18-30$. The exclusion criteria were as described above for the group of obese women.

Data collection - Subjects characteristics. All women filled in a questionnaire. They reported details referring to their daily diet, duration and regularity of menstruation, occurring bleedings, coexistent disease, ingestion of supplements and medication

Anthropometric measurements. Anthropometric measurements of subjects were carried out while they were wearing light clothing and without shoes. Weight was measured to the nearest $0.1 \mathrm{~kg}$ using digital scale TANITA model MC $980 \mathrm{MA}$, and height measured to the nearest $0.1 \mathrm{~cm}$. Body mass index (BMI) was calculated using Quetelet's equation [weight $(\mathrm{kg}) /$ height $\left(\mathrm{m}^{2}\right)$ ]. Obesity was recognized if the BMI exceeded $30 \mathrm{~kg} / \mathrm{m}^{2}$. Waist circumference was measured at a level midway between the lower rib margin and the iliac crest, with the tape all around the body in a horizontal position at the end of normal expiration. Waist measurement was carried out to the nearest $0.5 \mathrm{~cm}$. Hip circumference was measured at the level of femoral trochanters. Waist to hip ratio (WHR) was calculated for each patient.

Dietary assessment. All obese women obtained an individually adjusted dietary plan with an energy content of $1,500 \mathrm{kcal}$. The advised diet consisted of $50-55 \%$ carbohydrates, $25-30 \%$ fat and $15-20 \%$ protein. The intake of sacharose was minimized to $<10 \%$ of total ingested energy. The content of dietary fibre was above $30 \mathrm{~g}$ per day. Vitamin and mineral requirements were covered. All women were advised to maintain their physical activity by fast walking for 150 minutes per week.
Laboratory measurements. Blood glucose, insulin, lipids, ferritin, TIBC and iron concentrations were assayed in serum obtained from a venous blood sample. Blood was drawn from the antecubital vein following overnight fasting (10$12 \mathrm{~h})$. Serum levels of glucose, insulin, trigicerides ( $\mathrm{Tg}$ ), total cholesterol (TC), low-density lipoproteins (LDL-C), highdensity lipoproteins (HDL -C), C-reactive protein (CRP), ferritin and iron were assayed in the central laboratory of the University Hospital in Poznan. Ferritin was assayed using the automatic immunologic method of the Roche Company, based on agglutination reaction enhanced by latex particles. Iron was assayed using an automatic method with ferrozin without protein removal. Iron binding capacity was measured by saturating transferrin with iron chloride solution, followed by iron concentration measurement according to a previously described method. Transferrin saturation was calculated based on a standard equation [iron concentration ug/dl / TIBC ug/dl]. Oral glucose tolerance test (OGTT) with $75 \mathrm{~g}$ of glucose was performed according to the standard procedure. Venous blood was drawn pre- and 2 hours post oral load with $75 \mathrm{~g}$ of glucose, and the serum level of glucose and insulin were assayed in both blood samples. Glucose concentration was assessed by an enzymatic method with hexokinase, glucose HK gen.3 (GLUC.3) and insulin concentration was assessed by electrochemiluminescence immunoassay (Cobas analyzer).

Bioimpedance (BIA). Bioimpedance measures were performed using the Akern device (Akern BIA 101, Florence, Italy). BIA method uses a current of $9 \mathrm{~V}$ passing through the right upper and lower part of the body while subject remains in a supine position on a bed, wearing light clothing. Electrodes were placed on the dorsal aspect of the right hand, one at the base of the right middle finger and the other at the level of the right wrist. The other 2 electrodes were placed on the anterior side of the right foot, one at the base of the $3^{\text {rd }}$ toe and the other at the level of the right ankle. The body tissue composition was analyzed using hand-to-foot resistance, and reactance determined by resistance and reactance from an alternating current $(50 \mathrm{kHz})$.

Statistical analysis. Statistical analysis was carried out using STATISTICA software for Windows, version 10 (StatSoft Inc., Tulsa, USA). Because the number of analyzed individuals in each group did not exceed 50, non-parametric statistical tests were used. The results obtained from obese women and non-obese control were compared by the U Mann-Whitney's test. The results obtained in the group of obese women during initial evaluation and after 8 weeks of the dietary regime were compared by the Wilcoxon's test. All values are presented as mean \pm standard deviation (SD). The correlation between various parameters measured in obese women during initial assessment was evaluated using the Spearman's test. For this analysis, the correlation coefficient was presented as $r$. A $p$ value below 0.05 obtained in above-mentioned tests was regarded as significant.

\section{RESULTS}

Obese vs. non-obese women. The obese women at the initial evaluation, in comparison to non-obese control women 

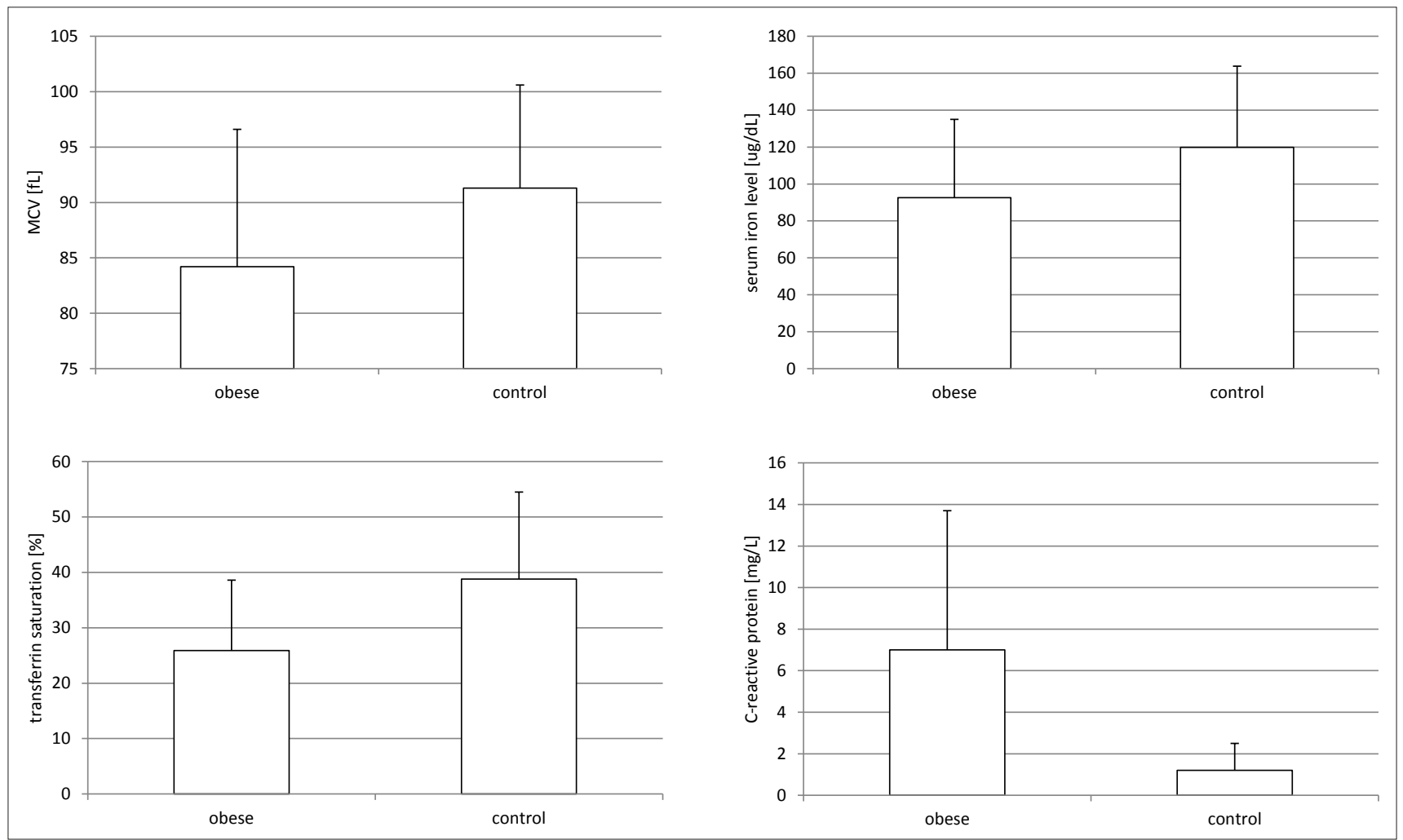

Figure 1. The obese women at the initial evaluation in comparison to non-obese control women

(Fig. 1), were characterized by a significantly lower mean red blood cell volume (MCV; 84.2 \pm 12.4 vs. $91.3 \pm 9.3 \mathrm{fL} ; \mathrm{p}<0,0001)$, serum iron level $(92.6 \pm 42.4$ vs. $119.8 \pm 44.0 \mu \mathrm{g} / \mathrm{dL} ; \mathrm{p}<0.01)$, and transferrin saturation (TSAT; $25.9 \pm 12.7$ vs. $38.8 \pm 15.7 \%$; $\mathrm{p}<0.01$ ), but by higher total iron binding capacity (TIBC; $367.2 \pm 51.7$ vs. $321.0 \pm 60.7 \mu \mathrm{g} / \mathrm{dL} ; \mathrm{p}<0.01$ ), and plasma level of the C-reactive protein (CRP; $7.0 \pm 6.7$ vs. $1.2 \pm 1.3 \mathrm{mg} / \mathrm{L}$; $\mathrm{p}<0.01)$.

Other haematologic parameters (haemoglobin level, red blood cell count, haematocrite), as well as ferritin level and erythrocyte sedimentation rate (ESR), were not significantly different in obese and non-obese women.
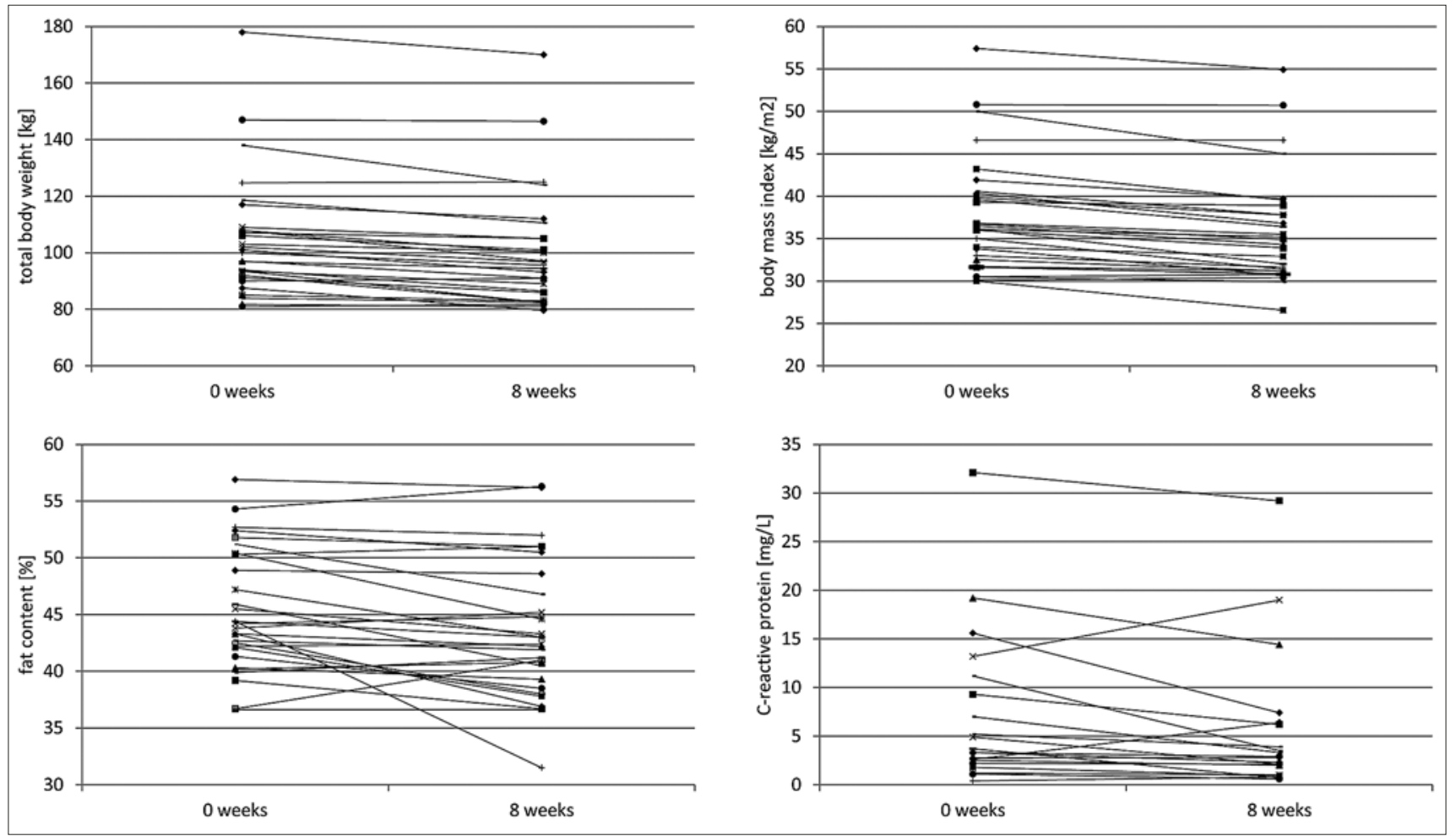

Figure 2. Effects of 8 week diet 

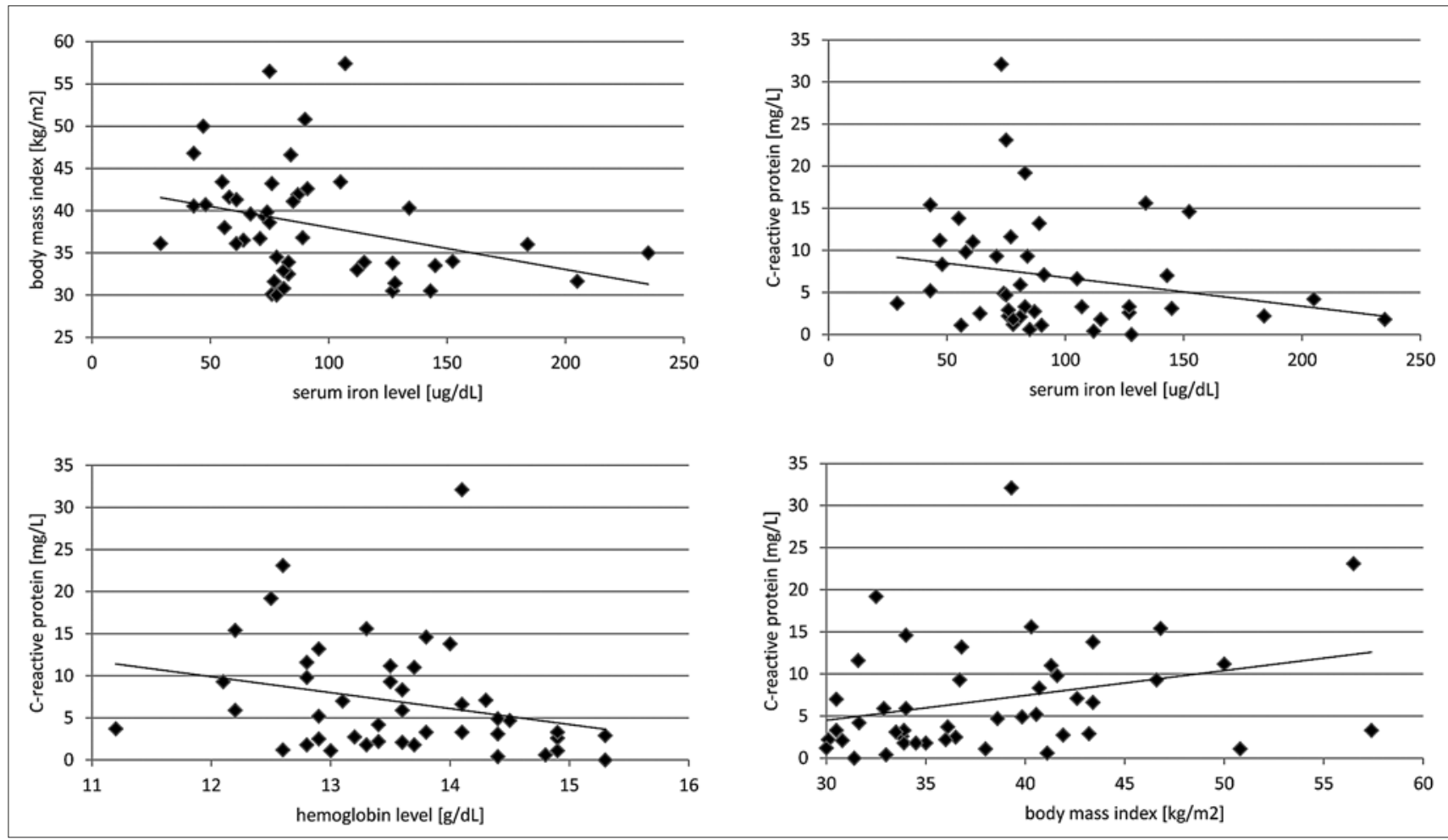

Figure 3. Relationship between measured parameters in obese women at the initial evaluation

Effects of 8 week diet. The obese women who were assessed at the beginning and after 8 weeks of diet (Fig. 2) decreased their mean total body weight from $104.1 \pm 21.3$ to $99.2 \pm 20.7 \mathrm{~kg}(\mathrm{p}<0,0001)$, as well as their BMI from $37.7 \pm 6.8$ to $35.8 \pm 6.5 \mathrm{~kg} / \mathrm{m}^{2}(\mathrm{p}<0,0001)$, and percentage content of fat tissue from $45.3 \pm 5.3$ to $43.5 \pm 6.0 \%$ ( $p<0.01)$. Those women decreased their mean waist and hip circumference from $104.4 \pm 15.9$ to $101.7 \pm 16.3 \mathrm{~cm}$ and from $124.2 \pm 13.6$ to $121.0 \pm 12.7 \mathrm{~cm}$, respectively; both $\mathrm{p}<0,001)$.

As a result of the 8 week diet, CRP decreased slightly but significantly from $6.9 \pm 7.1$ to $6.2 \pm 7.5$ ( $p<0.05)$. No significant changes were observed in haematologic and iron metabolism parameters during the 8 week period.

Relationships between measured parameters in obese women. In the obese women assessed initially (Fig. 3), an inverse correlation was observed between serum iron level and such obesity indicators as total body weight $(\mathrm{r}=-0.45$; $\mathrm{p}<0,01)$, BMI $(\mathrm{r}=-0.38 ; \mathrm{p}<0.01)$, percentage content of fat tissue $(\mathrm{r}=-0.43 ; \mathrm{p}<0.01)$, waist $(\mathrm{r}=-0.35 ; \mathrm{p}<0.05)$ and hip circumference $(\mathrm{r}=-0.47 ; \mathrm{p}<0.01)$. Concomitantly, iron level was inversely correlated with inflammatory parameters such as CRP $(\mathrm{r}=-0.30 ; \mathrm{p}=0.05)$ and ESR $(\mathrm{r}=-0.35 ; \mathrm{p}<0.05)$.

Haemoglobin level also was inversely correlated with CRP $(\mathrm{r}=-0.32 ; \mathrm{p}<0.05)$ and ESR $(\mathrm{r}=-0.38 ; \mathrm{p}<0.01)$, but positively with ferritin level $(r=0.40 ; p<0.05)$. A similar relationship was observed for haematocrit, which was negatively correlated with CRP $(\mathrm{r}=-0.30 ; \mathrm{p}<0.05)$ and ESR $(\mathrm{r}=-0.31 ; \mathrm{p}<0.05)$, but positively with ferritin $(\mathrm{r}=0.33 ; \mathrm{p}<0.05)$.

In addition, a positive correlation was observed between CRP and obesity indicators such as BMI $(r=0.33$; $\mathrm{p}<0.05)$ and percentage content of fat tissue $(r=0.32 ; \mathrm{p}<0.05)$, as well as plasma glucose level at the $120^{\text {th }}$ minute of oral glucose tolerance test (OGTT; $r=0.49 ; \mathrm{p}<0.001$ ). Similarly, ESR was positively correlated with the percentage content of fat tissue $(\mathrm{r}=0.34 ; \mathrm{p}<0.05)$, plasma glucose level at the $120^{\text {th }}$ minute of OGTT $(r=0.48 ; \mathrm{p}<0,001)$, and plasma insulin level at the $120^{\text {th }}$ minute of OGTT $(r=0.40 ; \mathrm{p}<0.01)$.

\section{DISCUSSION}

The first cross-sectional study assessing the prevalence of iron deficiency in overweight and obese individuals was performed in Israel in 2003. American studies revealed that overweight children are twice as likely to be iron deficient than normal weight children. Research conducted by Zimmermann et al. on a population from transition countries like Morocco, Thailand and India, revealed that iron absorption correlated negatively with BMI and C-reactive protein [9]. The same authors proved that BMI is a significant negative predictor of body iron. These findings indicate that greater BMI is associated with degraded iron status. There exist some expectation that inflammatory response also significantly affects iron the status towards causing decrease in iron stores. It is also well known that inflammation interferes with iron metabolism, and erythropoiesis causing anaemia of chronic disease (ACD), also known as anaemia of inflammation, confirmed in the presence of chronic inflammation (increased CRP level in the absence of other inflammatory cause), diminished haemoglobin level and a low TSAT [10-21].

The presented study also confirmed that obese women exhibit a statistically significantly lower level of serum iron, TSAT and MCV, compared to healthy individuals. The responsible mechanism is not fully understood, but it is believed that an increased level of pro-inflammatory cytokines, such as C-reactive protein, activates hepcidin expression, consecutively leading to restriction in intestinal iron absorption and macrophage iron release through hepcidin downregulating influence on ferroportin-1 [22]. It 
is thought that hepcidin inhibits expression of ferroportin 1 , limiting iron absorption in duodenum, and iron ex-flux from cells to the plasma [23]. In the population of obese women in the current study, the level of C-reactive protein was significantly higher than in the control group, which may be responsible for deterioration in iron homeostasis. It has already been proved that the status of inflammation (C-reactive protein $>10 \mathrm{mg} / \mathrm{dL}$ ) causes increase in the serum hepcidin level, and consecutively leads to iron depletion [14]. The presented study confirmed an inverse correlation between CRP and iron level, although the hepcidin level was not assessed. Similar to the results obtained by Yanoff, a positive correlation between C-reactive protein and BMI was found in the current study, confirming that obesity is associated with a low-grade inflammatory status that promotes release of acute-phase molecules [10,22].

This study also proves also that there is an inverse correlation between serum iron level and such obesity indicators as total body weight, BMI, percentage content of fat tissue, waist and hip circumference. It is stated that increased body fat, especially visceral fat, predisposes towards worse iron homeostasis due to an increased rate of pro-inflammatory cytokines produced by visceral adipose tissue [20-25]. A large-scale study conducted on obese patients revealed also a positive correlation between TIBC and the percentage content of fat tissue. This was not confirmed in the presented, although a statistically significantly higher level of TIBC was observed in obese women compared to normal-weight controls. A positive correlation was also observed between LDL-cholesterol level and haemoglobin level, as described previously by Datz [25].

It is worth mentioning that after 8 weeks of a low calorie diet, a significant decrease in C-reactive protein was observed in subjects who achieved weight loss; however, at the same time, haematologic indices did not improve. Recent data shows that weight loss in obese individuals is associated with a lower hepcidin level and therefore ann improvement in iron absorption [23]. This finding, however, was not confirmed in the current study.

In the past, researchers believed that poor dietary choices were responsible for iron deficiency in obese individuals, but there is little data to support this assumption [22, 25]. A study conducted by Menzie et al. revealed that dietary iron intake and its estimated bioavailability are similar in obese and normal weight subjects $[22,24]$. On the other hand, an increased level of proinflammatory cytokines, adipokines and hepcidin, may impair iron absorption [22]. Moreover, different studies have confirmed the fact that a higher BMI predicts an impaired response to iron fortification, which additionally leads to impaired iron homeostasis in obese subjects. It is crucial to prevent the combination of obesity and obesity-related hypoferraemia, because the conjunction of those two disorders is more detrimental than obesity or iron deficiency alone, and may cause decreased exercise capacity as well as impaired cognitive function [25].

\section{Acknowledgement}

This study was performed under Clinical Research No.: 1274/B/P01/2010/38, entitled: The influence of nutritional and pharmacological therapy on hormone profile: ghrelin, adiponectin, IGF-1 and insulin in the treatment of obesity and its complications.

\section{REFERENCES}

1. Rizza S, Federici M. Cytokines and metabolic syndrome: The perfect storm for arterial aging. Atherosclerosis 2011; 215: 284-285.

2. Neymotin F, Sen U. Iron and obesity in females in United States. Obesity 2011: 19(1): 191-199.

3. Abbott MJ, Tang T. The role of phospholipase A2-derived mediators in obesity. Drug Discov Today Dis Mech. 2010; 7: 213-218.

4. McClung JP, Karl J.P. Iron deficiency and obesity: the contribution of inflammation and diminished iron absorption. Nutr Rev. 2009; 67(2): 100-104.

5. Tussing-Humphreys L, Pini M. Suppressed cytokine production in whole blood cultures may be related to iron status and hepcidin and is partially corrected following weight reduction in morbidly obese pre-menopausal women. Cytokine 2011; 53: 201-206.

6. Marzo VD. Novel mechanisms in obesity, type 2 diabetes and accompanying inflammation: focus on lipid signaling. Drug Discov. Today Mech. 2010; 7: 159-161.

7. Konner AC, Bruning JC. Toll-like receptors: linking inflammation to metabolism. Trends in Endocrinol. Met. 2011; 22(1): 16-23.

8. Cheng HL, Bryant C. The relationship between obesity and hypoferraemia in adults: a systematic review. Obes Rev. 2011

9. Zimmermann MB, Zeder C. Adiposity in women and children from transition countries predicts decreased iron absorption, iron deficiency and reduced response to iron fortification. Int J Obes. 2008; 32: 10981104.

10. Yanoff LB, Menzie CM. Inflammation and iron deficiency in the hypoferremia of obesity. Int J Obes. 2007; 31: 1412-1419.

11. Munoz M, Garcia-Erce J. Disorders of iron metabolism. Part I: molecular basis of iron homeostasis. J Clin Pathol. 2011; 46: 281-284.

12. Corwin HL, Krantz SB. Anemia of the critically ill: „,acute” anemia of chronic disease. Crit Care Med. 2000; 28: 3098-3099.

13. Vokurka M, Lacinova Z. Hepcidin expression in adipose tissue increases during cardiac surgery. Physiol Res. 2010; 59: 393-400.

14. Ganz T, Olbina G. Immunoassay for human serum hepcidine. Blood 2008; 15(112): 4292-4297.

15. Hintze KJ, Snow D. Adipocyte hypoxia increases hepatocyte hepcidin expression. Biol Trace Elem Res. 2011; 143: 764-771.

16. Bekri S, Gual P. Increased adipose tissue expression of hepcidin in severe obesity is independent from diabetes and NASH. Gastroenterol. 2006; 131: 788-796.

17. Pini M, Rhodes DV. Hematological and acute-phase responses to diet-induced obesity in IL-6 KO mice. Cytokine 2011; 56(3): 708-716.

18. Huang H, Constante M. Contribution of STAT3 and SMAD4 pathways to the regulation of hepcidin by opposing stimuli. Blood 2009; 113(15): 3593-3599.

19. Munoz M, Garcia-Erce JA. Disorder of iron metabolism. Part II: iron deficiency and iron overload. J Clin Pathol. 2011; 64: 287-296.

20. Claria J. Resolvins, protectins and other lipid mediators in obesityassociated inflammatory disorders. Drug Discov Today Mech. 2010; 7: 219-225

21. Grinchuk V, Yang Z. IL-25-induced immunotherapy against obesity and the associated metabolic syndrome. AGA abstracts 191(44)

22. Aeberli I, Hurrell RF, Zimmermann MB. Overweight children have higher circulating hepcidin concentrations and lower iron status but have dietary iron intakes and bioavailability comparable with normal weight children. Int J Obes. 2009; 33: 1111-1117.

23. Cepeda-Lopez AC, Osendarp S, Melse-Boonstra A. Sharply higher rates of iron deficiency in obese Mexican women and children are predicted by obesity-related inflammation rather than by differences in dietary iron intake. Am J Clin. Nutr. 2011; 93: 975-983.

24. Menzie CM, Janoff LB, Denkinger BI et al. Obesity-related hypoferremia is not explained by differences in reported intake of heme and nonheme, iron or intake of dietary factors that can affect iron absorption. J Am Diet Assoc. 2008; 108: 145-148.

25. Datz C, Felder TK, Niederseer D et al. Iron homeostasis in the metabolic syndrome. Eur J Clin Invest. 2013. 